\title{
DESENVOLVIMENTO SUSTENTÁVEL: UMA ANÁLISE A PARTIR DA PERSPECTIVA DOS BRICS
}

\section{DESARROLLO SOSTENIBLE: UN ANÁLISIS DESDE LA PERSPECTIVA DEL BRICS}

Renato Pinto Cavalcanti ${ }^{*}$

Resumo: O seguinte estudo visa analisar de forma objetiva a relação entre os países que compõem o agrupamento conhecido como BRICS - Brasil, Rússia, India, China e África do Sul - e o desenvolvimento sustentável, questionando se existe uma dissonância entre este elemento e as políticas adotada pelos referidos países. Para isto, busca explorar elementos essenciais ao entendimento do problema, como o meio ambiente, o desenvolvimento sustentável e a governança ambiental internacional. Este artigo fez uso do estudo exploratório, mediante pesquisa bibliográfica e documental, através da análise e obtenção de informações constantes em livros, artigos, relatórios e resoluções, constantes em bibliotecas e na internet. Quanto aos objetivos foi utilizado o método analítico-descritivo, com uma abordagem qualitativa, visando à análise do atual contexto do Direito Internacional, especificamente voltado ao meio ambiente e ao desenvolvimento sustentável, e a comparação de seus ditames com a realidade dos países que compõem o BRICS.

Resumen: El siguiente estudio tiene como objetivo analizar objetivamente la relación entre los países que conforman la agrupación conocida como BRICS - Brasil, Rusia, India, China y Sudáfrica - y el desarrollo sostenible, cuestionando si hay una disonancia entre este elemento y las políticas adoptadas por estos países. Para ello, se busca explorar esenciales para la comprensión del problema, tales como el medio ambiente, el desarrollo sostenible y la gobernanza ambiental a nivel internacional. En este artículo se hace uso del estudio exploratorio de la investigación bibliográfica y documental, mediante el análisis y la obtención de la información contenida en libros, artículos, informes y resoluciones, que figuran en las bibliotecas y en Internet. En cuanto a los objetivos se utilizó el método de análisis descriptivo, con enfoque cualitativo, cuyo objetivo es analizar el contexto actual del derecho internacional, orientado específicamente

\footnotetext{
* Faculdade de Ciências Sociais Aplicadas, Brasil.

E-mail: renatopintoster@gmail.com

Recibido: 21/12/2016. Aceptado: 30/01/2018.
} 
para el medio ambiente y el desarrollo sostenible, y la comparación de sus dictados con la realidad de los países que conforman la BRICS.

Palavras-chave: Meio ambiente, Direito ambiental internacional, Desenvolvimento sustentável, Governança, BRICS

Palabras clave: Medio Ambiente, Derecho ambiental internacional, Desarrollo sostenible, Gobernanza, BRICS

\section{INTRODUÇÃO}

Em sua missão incansável para atingir o ápice do desenvolvimento econômico, a humanidade atuou de forma predatória e destrutiva sobre o meio-ambiente. Antes por ignorância e, atualmente, pelo capitalismo desenfreado, é certo que as políticas adotadas pelos Estados e demais agentes impactantes apenas nos levarão rumo à condições ambientais cada vez mais precárias.

Tendo em vista esta desgraça iminente, faz-se necessário a elaboração e implementação de diretrizes e normas lato sensu que tenham como objetivos a preservação da natureza e amenização dos impactos causados pelo homem. Assim, a criação de agrupamentos políticos visando à cooperação internacional na adoção de medidas e tomada de decisões conjuntas, surge como uma excelente alternativa para efetivação de tais políticas positivas.

Dentre estes agrupamentos, destacam-se os BRICS, grupo composto por cinco Estados emergentes: Brasil, Rússia, Índia, China e África do Sul; que, devido às suas semelhanças nas searas político, econômico e social, apresentam enorme potencial na representação da governança global, podendo contribuir consideravelmente na temática sustentável.

Desta feita, existe por parte destes Estados o compromisso de disciplinar e definir padrões de conduta adequados para alcançarem a conservação do meio-ambiente no cenário internacional, invocando, para tanto, as reflexões e ensinamentos do Direito Internacional do Meio Ambiente; enquanto garantem o desenvolvimento social de suas populações, através de políticas públicas destinadas a esta finalidade.

Em face dos aspectos suscitados, é válido o seguinte questionamento: na conjuntura atual de uma sociedade marcada pelo desenvolvimento econômico, é possível determinar a presença de políticas nos países que compõem os BRICS voltadas à consolidação do desenvolvimento sustentável? Como se dá a atuação daqueles países com relação a este tema?

Contudo, primeiramente, faz-se necessária a explanação de alguns temas para entendermos melhor a presente pesquisa, quais 
sejam: o meio ambiente e o Direito Internacional do Meio Ambiente, introduzindo aspectos de sua natureza e alguns princípios importantes; o desenvolvimento sustentável, conceito chave para a nossa pesquisa e; a Governança ambiental internacional, expondo sua importância na elaboração de políticas eficazes. Por estarem interligados, são imprescindíveis na compreensão da problemática apresentada, e então, poderemos ingressar nas perspectivas dos países que compõem o BRICS.

Assim, temos como objetivo esclarecer aqueles conceitos, facilitando o entendimento e a percepção da relevância deles para a nossa análise. A finalidade da presente pesquisa é doutrinária, explorando e discutindo tais temas e contextualizando-os na realidade dos BRICS, elaborando uma breve análise de cada caso, em particular.

Nosso estudo é de suma importância para o debate jurídico acerca deste tema, pouco explorado no nosso cotidiano enquanto apreciadores do Direito. Além de ser um objeto de estudo ainda em crescimento devido à sua atualidade e complexidade, a reflexão sobre como as nossas ações influenciam no mundo ao nosso redor é totalmente necessária.

\section{MEIO AMBIENTE E O DIREITO AMBIENTAL INTERNACIONAL}

Definir objetivamente o Meio Ambiente não é tarefa fácil, haja vista existirem diversas interpretações para seu conceito. Basicamente, Meio Ambiente é o conjunto de condições externas de natureza química, física e biológica, que regem e abrigam todas as formas de vida e seus organismos. Além do sentido natural, pode-se também ser definido de uma forma mais ampla, como um conjunto de ações ou circunstâncias, de origens culturais, sociais e econômicas.

O desenvolvimento sustentável está no cerne do meio ambiente, sendo impossível abordar ambos os termos sem entendê-los em suas totalidades. Conforme será explanado adiante, a ideia central do desenvolvimento sustentável é a obtenção de um crescimento econômico e social garantindo a preservação do meio ambiente para as gerações presentes e futuras.

Sendo a base de existência da vida no nosso planeta, ao meio ambiente passou a ser reconhecida a necessidade de criação de um ramo especial de doutrinas e legislações a nível internacional, a fim de protegê-lo e preservá-lo. Apesar de já existirem algumas legislações esparsas visando à preservação ambiental, foi tão somente em junho de 1972, em Estocolmo, na Suécia, durante a $1^{\text {a }}$ Conferência das Nações Unidas Sobre o Meio Ambiente, que o Direito Ambiental consolidouse. Com a Declaração Universal do Meio Ambiente, aprovada naquela Conferência, o ar, a água, o solo, a fauna e a flora passaram a ser objeto de preservação pelas mais diversas legislações que viriam a surgir mundo 
afora. Nos dizeres de Dinh:

O direito internacional do ambiente é então constituído pelo conjunto de normas jurídicas internacionais necessárias à protecção deste espaço, a biosfera (ou ecossistema global) definição que coloca claramente ao mesmo tempo em evidência o seu carácter funcional - trata-se de enquadrar as actividades humanas que degradam o ambiente, ou sejam susceptíveis de atentar contra ele - e a sua integração no direito internacional geral ${ }^{1}$.

Assim, com o processo de globalização e de internacionalização dos direitos, o Direito Ambiental Internacional tornou-se um ramo essencial e o seu objeto, o meio ambiente, mais especificamente no que se refere à sua proteção e melhoramento, passou a ser considerado como uma questão fundamental na manutenção da dignidade da pessoa humana, sendo a principal agenda do século XXI.

Como em toda área do Direito, que apresenta natureza autônoma, há uma base principiológica, o Direito Ambiental Internacional também a possui. Tais princípios atuam tanto como norte na criação de normas como na interpretação e no preenchimento de lacunas presentes nos ordenamentos já existentes. Dentre inúmeros destes, podemos destacar os mais importantes, quais sejam: o princípio da dignidade da pessoa humana, do poluidor-pagador e da prevenção e precaução; a serem explanados a seguir.

\subsection{Princípio da dignidade humana}

Talvez o princípio mais importante de qualquer ramo do direito, a dignidade da pessoa humana deve existir em qualquer ambiente que prestigie os direitos humanos e o ideal da democracia. Tal princípio é invocado tão longo nos primeiros dois artigos da Declaração Universal do Meio Ambiente, bem como na Declaração do Rio sobre Meio Ambiente e Desenvolvimento, documento elaborado durante a Conferência das Nações Unidas sobre Meio Ambiente e Desenvolvimento - Rio 92. Seu Princípio 1 alude que: "Os seres humanos estão no centro das preocupações com o desenvolvimento sustentável. Tem direito a uma vida saudável e produtiva, em harmonia com a natureza”.

$\mathrm{Na}$ lição de Ingo Wolfgang Sarlet, citada por Guerra, podemos extrair que:

Temos por dignidade da pessoa humana a qualidade intrínseca e distintiva de cada ser humano que o faz merecedor do mesmo respeito e consideração por parte do Estado e da comunidade, implicando, neste

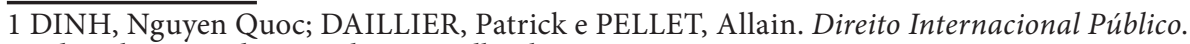
$2^{\mathrm{a}}$ ed. Lisboa: Fundação Calouste Gulbenkian, 2003. p. 1297. 
sentido, um complexo de direitos e deveres fundamentais que assegurem a pessoa tanto contra todo e qualquer ato de cunho degradante e desumano, como venham a lhe garantir as condições existenciais mínimas para uma vida saudável, além de propiciar e promover sua participação ativa co-responsável nos destinos da própria existência e da vida em comunhão dos demais seres humanos ${ }^{2}$.

Já Barroso revela outros aspectos da dignidade da pessoa humana que merecem ser citados:

[...] a dignidade da pessoa humana é parte do conteúdo dos direitos materialmente fundamentais, mas não se confunde com qualquer deles. Nem tampouco é a dignidade um direito fundamental em si, ponderável com os demais. Justamente ao contrário, ela é o parâmetro da ponderação, em caso de concorrência entre direitos fundamentais. Em segundo lugar, embora seja qualificada como um valor ou princípio fundamental, a dignidade da pessoa humana não tem caráter absoluto. [...] Uma última anotação: a dignidade da pessoa humana, conforme assinalado acima, se aplica tanto nas relações entre indivíduo e Estado como nas relações privadas ${ }^{3}$.

Resta demonstrada, então, a verdadeira importância do referido princípio nas relações humanas. É certo que sua constante presença em discussões, convenções, debates etc. ajudam a fortalecer os ideais democráticos e evitar políticas, por parte dos Estados, que configurem retrocessos aos direitos humanos.

\subsection{Princípios da prevenção e precaução}

Estes princípios apresentam certa semelhança no tocante às suas definições, contudo, não devem ser confundidos. Enquanto que, utilizando uma definição breve, o princípio da precaução visa evitar ao máximo a possibilidade de que ocorra algum dano ao meio ambiente, o princípio da prevenção reina em um contexto mais concreto, quando já são conhecidos os impactos ambientais e deve-se agir de maneira a evitar impactos futuros.

Quanto ao princípio da precaução, é válido salientar que este sofre certa limitação, pois depende da tecnologia disponível no momento

2 SARLET, 2001 apud GUERRA, Sidney e EMERIQUE, Lilian Márcia Balmant. O Princípio da Dignidade da Pessoa Humana e o Mínimo Existencial. Revista da Faculdade de Direito de Campos. 2006, vol 9, p. 382. Disponível em <http://fdc.br/Arquivos/Mestrado/Revistas/ Revista09/Artigos/Sidney.pdf>

3 BARROSO, Luís Roberto. A Dignidade da Pessoa Humana no Direito Constitucional Contemporâneo: Natureza Jurídica, Conteúdos Mínimos e Critérios de Aplicação. [s.l.], 2010, BARROSO, 2010, p. 14-15. Disponível em: <https://www.luisrobertobarroso.com.br/wpcontent/uploads/2010/12;Dignidade_texto-base_11dez2010.pdf> 
e também da percepção dos encarregados de aferir os riscos em uma determinada situação fática, em decorrência da sua natureza de imprevisibilidade e incerteza. Como bem diz Antunes:

Em vários casos, a norma deve incidir sobre realidades factuais e se localizam na fronteira da investigação científica e, por isso, nem sempre a ciência pode oferecer ao Direito a tranqüilidade da certeza. Aquilo que hoje é visto como inócuo amanhã poderá ser considerado extremamente perigoso e vice-versa ${ }^{4}$.

Em contrapartida, o princípio da prevenção, contando com o dom da certeza, pode ser mais facilmente invocado. Ferramentas como o licenciamento ambiental e o estudo e relatório de impacto ambiental (EIA/RIMA) ajudam na identificação de prováveis impactos futuros, para que sejam estes efetivamente evitados.

\subsection{Princípio do poluidor-pagador}

Introduzido pela Organização para a Cooperação e Desenvolvimento Econômico - OCDE, em 25 de maio de 1972, através da Recomendação C(72) $128^{5}$, o princípio do poluidor-pagador surge como um meio de minimizar ou mitigar o impacto causado por determinada atividade danosa ao ambiente, ao transferir da sociedade o ônus da degradação para o degradante, ou seja, o utilizador dos recursos ambientais.

Pode-se dizer que o referido princípio está concatenado no da prevenção, explanado anteriormente, haja vista possuir um caráter dúplice, quais sejam: prevenir a ocorrência do dano (caráter preventivo), e, quando este já tem ocorrido, repará-lo (caráter repressivo).

Por fim, como bem observa Fiorillo ${ }^{6}$, deveras errônea é a noção de que este princípio serve como uma espécie de "permissão para poluir", como se o pagamento pela poluição autorizasse o poluidor a utilizar os recursos naturais a seu bel-prazer.

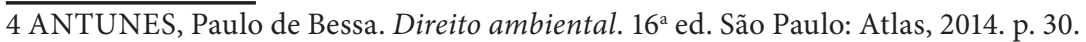

5"Cost Allocation: the Polluter-Pays Principle Environmental resources are in general limited and their use in production and consumption activities may lead to their deterioration. When the cost of this deterioration is not adequately taken into account in the price system, the market fails to reflect the scarcity of such resources both at the national and international levels. Public measures are thus necessary to reduce pollution and to reach a better allocation of resources by ensuring that prices of goods depending on the quality and/or quantity of environmental resources reflect more closely their relative scarcity and that economic agents concerned react accordingly" Organization for Economic co-operation and Development - OECD. Guiding Principles Concerning International Economic Aspects of Environmental Policies. Recommendation C(72) 12. Disponível em: <http://www.oecd.org>

6 FIORILLO, Celso Antonio Pacheco. Curso de direito ambiental brasileiro. $15^{\text {a }}$ ed. São Paulo: Saraiva, 2014, p. 81-82. 


\section{DESENVOLVIMENTO SUSTENTÁVEL}

Considerado por muitos doutrinadores como um princípio do meio ambiente, o desenvolvimento sustentável merece um tópico à parte devido a sua importância no presente trabalho.

Desde o início de nossa breve história neste planeta, a humanidade tem causado impactos na natureza. Antes apenas objetivando sua subsistência, o ser humano tinha a capacidade de coexistir com um meio ambiente equilibrado. Contudo, com o surgimento de novas tecnologias e uma cultura que incentiva o consumo exagerado de bens e serviços, passamos a ter mais acesso aos recursos ambientais, gerando, consequentemente, uma exploração desenfreada e um verdadeiro predatismo ambiental.

Conforme Carvalho:

A crise ambiental surgiu a partir do momento em que a humanidade passou a se considerar em um plano isolado, sem qualquer interdependência em relação ao meio ambiente natural. Essa concepção de sociedade mecanicista gerou a atividade predatória e inconsciente com a percepção de que o ser humano não seria afetado pela escassez e degradação ambiental ${ }^{7}[\ldots]$.

A desconsideração, por uma grande parcela dos seres humanos, de que fazemos parte do meio ambiente, gera certa apatia ou indiferença ante os cada vez mais comuns desastres e impactos ambientais causados pela irresponsabilidade de certas pessoas. Há uma clara letargia dos governantes e demais autoridades, muitas vezes em decorrência de interesses pessoais. Para Jonas ${ }^{8}$, "a solidariedade de destino entre o ser humano e a natureza faz igualmente redescobrir a dignidade autônoma da natureza e obriga a respeitar a sua integralidade, além do aspecto utilitário".

Tendo em vista esta problemática, passou-se a ser discutida pela comunidade internacional a ideia do desenvolvimento sustentável. Introduzida em certos pontos na Declaração de Estocolmo, tal instituto só passou a ser expresso solenemente na Rio-92. Nesta ocasião, foi elaborado um plano de ação, voltado a viabilizar a adoção de medidas que promovam o desenvolvimento sustentável, a Agenda 21, reforçando a "ideia de que o desenvolvimento e a preservação do meio ambiente devem andar pari passo" ". Sobre a Declaração do Rio, merecem destaque os seguintes princípios:

7 CARVAlHO, Sonia Aparecida e ADOLFO, Luiz Gonzaga Silva. Sustentabilidade e tecnologia: perspectivas para o direito contemporâneo. Direito e desenvolvimento sustentável: a (necessária) proteção jurídica da biotecnologia e a (necessária) regulamentação do acesso à biodiversidade e aos conhecimentos tradicionais. Passo Fundo: IMED, 2013, p. 171.

8 JONAS, 2006 apud CARVALHO, 2013, p. 172.

9 NUSDEO, Ana Maria de Oliveira. Desenvolvimento sustentável do Brasil e o Protocolo de Quioto. São Paulo: Editora Revista dos Tribunais, 2011, vol 6, p. 57. 
Princípio 1. Os seres humanos estão no centro das preocupações com o desenvolvimento sustentável. Têm direito a uma vida saudável e produtiva, em harmonia com a natureza.

[...]

Princípio 3. O direito ao desenvolvimento deve ser exercido de modo a permitir que sejam atendidas equitativamente as necessidades de desenvolvimento e de meio ambiente das gerações presentes e futuras. Princípio 4. Para alcançar o desenvolvimento sustentável, a proteção ambiental constituirá parte integrante do processo de desenvolvimento e não pode ser considerada isoladamente deste ${ }^{10}$.

Sendo assim, o conceito de desenvolvimento sustentável é exatamente aquele expresso no Princípio 3, que, em outras palavras, quer dizer que a satisfação das necessidades das gerações presentes não devem comprometer a possibilidade de igual satisfação das necessidades das gerações futuras. A este conceito basilar, foi dado o nome de equidade intergeracional. Ademais, Nusdeo lembra que o desenvolvimento sustentável

Relaciona-se, assim, com todas as políticas públicas voltadas ao estímulo de formas de utilização dos recursos naturais no processo de produção econômica e reprodução social que permita sua conservação ou renovação para o uso futuro das presentes e próximas gerações ${ }^{11}$.

Consoante a lição de Dinh, ao discorrer sobre a equidade intergeracional, tem-se que

Fundamentado na constatação fundamental de que os recursos naturais do globo são esgotáveis e não renováveis, este princípio tem por consequência que todo o Estado "tem o dever de cuidar que as actividades exercidas nos limites da sua jurisdição ou sobre o seu controlo não causem danos que possam afectar a vida das gerações presentes e futuras" (resolução supracitada do IDI, artigo $6^{\circ}$ ). A exigência de uma exploração racional e equitativa dos recursos naturais, em particular mas não exclusivamente os "recursos partilhados", encontra o seu prolongamento e a sua concretização nos princípios da prevenção e da precaução, cujo respeito é indispensável à realização do desenvolvimento sustentado ${ }^{12}$.

Ocorre que, para alcançar o pleno desenvolvimento sustentável, são

10 Declaração do Rio sobre Meio Ambiente e Desenvolvimento, 1992, Disponível em: <http:// www.onu.org.br/rio20/img/2012/01/rio92.pdf> Acesso em 17 de novembro de 2015.

11 NUSDEO. Op. cit., 2005, p. 58.

12 DINH. Op. cit., 2003, p. 1333. 
necessárias, em muitos casos, a adoção de políticas públicas por demais onerosas e a facilidade no acesso a tecnologias avançadas. Sendo assim, os países de terceiro mundo, com seus problemas sociais e econômicos, encontram vários óbices na persecução deste desenvolvimento.

Assim, também faz parte da agenda desenvolvimentista a cooperação entre os Estados, de modo que os países de primeiro mundo têm a obrigação de auxiliar os países menos desenvolvidos a conciliar o desenvolvimento com a preservação ambiental, reconhecendo suas responsabilidades comuns. Dinh, em sua obra, descreve muito bem este conceito:

A primeira função do conceito está então em reconciliar os pontos de vista dos países industrializados, preocupados com o futuro ecológico do planeta - que a sua industrialização quase não poupou - e os Estados do Terceiro Mundo, preocupados em primeiro plano com o seu próprio desenvolvimento econômico [...]. Nesta perspectiva, ele traduz-se no reconhecimento de responsabilidades comuns, mas diferenciadas dos Estados em matéria de protecção do ecossistema mundial ${ }^{13}$.

Portanto, o desenvolvimento sustentável agrega diversas qualidades essenciais aos seres humanos, no momento em que se deve haver um equilíbrio entre os fatores ecológicos, econômicos, sociais e tecnológicos para que aquele seja efetivado, Nesta ótica, podemos perceber que o desenvolvimento sustentável e um meio ambiente equilibrado se caracterizam como direitos fundamentais inerentes às pessoas humanas, e a proteção do meio ambiente é dever do Estado e da sociedade civil ${ }^{14}$.

\section{GOVERNANÇA AMBIENTAL INTERNACIONAL}

Devido ao fato dos Estados possuírem independência nas suas relações com as organizações internacionais e com outros Estados, não é raro que algum governo encontre dificuldades ao lidar com os demais. Contudo, para alcançar a máxima efetividade na elaboração, condução, gerenciamento etc. das políticas voltadas à proteção do meio ambiente e efetivação do desenvolvimento sustentável, é de extrema importância a criação de núcleos de cooperação entre nações.

Tais grupos fortalecem a união entre os Estados, fundada em interesses comuns, se diferenciado dos governos propriamente ditos na maneira informal de alcançar seus objetivos, prescindindo do poder de polícia para que os indivíduos aceitem suas políticas e resistam a suas proposições. A este tipo de governo (lato sensu, diga-se de passagem),

13 DINH, 2003, p. 1333.

14 CARVALHO, 2013, Op. cit., p. 179. 
foi dado o nome de Governança Global. Sua definição, dada pela Organização das Nações Unidas - ONU é a de que seria:

A soma de leis, normas, políticas e instituições que definem, constituem e mediam as relações transfronteiriças entre Estados, culturas, cidadãos, governamentais ou não-governamentais, e o mercado. Abrange a totalidade de instituições, políticas, regras, práticas, normas, procedimentos e iniciativas nas quais Estados e seus cidadãos [...] tentam trazer mais previsibilidade, estabilidade e ordem nas suas respostas frente a desafios transnacionais - como mudança climática, degradação ambiental, proliferação nuclear e terrorismo - que vão além da capacidade de um único Estado resolver ${ }^{15}$.

Ainda, conforme James Rosenau, em sua brilhante visão sobre a governança global, diz que:

[...] governança não é o mesmo que governo. Os dois conceitos referem-se a um comportamento visando a um objetivo, a atividades orientadas para metas, a sistemas de ordenação; no entanto, o governo sugere atividades sustentadas por uma atividade formal, pelo poder de polícia que garante a implementação das políticas devidamente instruídas, enquanto governança refere-se a atividades apoiadas em objetivos comuns, que podem ou não derivar de responsabilidades legais e formalmente prescritas e não dependem, necessariamente, do poder de polícia para que sejam aceitas e vençam resistências. Em outras palavras, governança é um fenômeno mais amplo do que governo; abrange as instituições governamentais, mas implica também mecanismos informais, de caráter não-governamentais, que fazem com que as pessoas e as organizações dentro de sua área de atuação tenham uma conduta determinada, satisfaçam suas necessidades e respondam às suas demandas ${ }^{16}$.

Analisando a conceituação feita por Rosenau, a governança global surge como uma forma de descentralizar a condução das políticas globais das mãos dos Estados. Seria uma diluição dos poderes decisórios, aumentando as possibilidades de surgirem novos atores globais, como

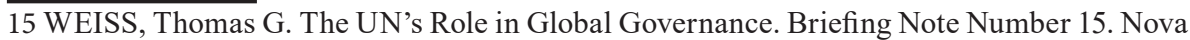
Iorque, 2009. Disponível em: $<$ http://www.unhistory.org/briefing/15GlobalGov.pdf $>$. Acesso em 19 de novembro de 2015. Tradução nossa.

16 Rosenau, 2000 apud NÓBREGA, NÓBREGA, Mariana de Oliveira e LACERDA, Jan Marcel de Almeida Freitas. Governança global ambiental e os BRICS: perspectivas e desafios para uma futura agenda sustentável. In: $2^{\circ}$ Seminário de Relações Internacionais: Graduação e Pós-graduação "Os BRICS e as Transformações da Ordem Global". João Pessoa - PB: Associação Brasileira de Relações Internacionais, 2014., p. 2-3. Disponível em <http:// www.seminario2014.abri.org.br/resources/anais/21/1412110561_ARQUIVO_Artigo-ABRIBRICSeGovernancaGlobalAmbiental.pdf>. Acesso em 07 de julho de 2015. 
as ONGs e demais organizações internacionais, atuando diretamente nos processos de tomada de decisões, regulação e elaboração de tais políticas.

Especificamente na área do Direito Internacional do Meio Ambiente, a Governança Ambiental é considerada, nas palavras de Agrawal e Lemos, citados por Nóbrega, como sinônimo de:

[...] intervenções visando à troca de incentivos relacionados com o ambiente, o conhecimento, as instituições, a tomada de decisões e os comportamentos. [...] usamos 'governança ambiental' para se referir ao conjunto de processos regulatórios, mecanismos e organismos através dos quais atores políticos influenciam ações ambientais e resultados [...]. A chave para as diferentes formas de governança ambiental são as relações político-econômicas que encarnam e como essas relações compartilham identidades, ações e resultados. Acordos internacionais, políticas e legislação nacionais, as estruturas locais de tomada de decisão, instituições transnacionais e ONGs ambientais são exemplos de formas através dos quais governança ambiental ocupa lugar [...]. Governança ambiental é variada em forma, fundamental em importância, e quase onipresente em propagação ${ }^{17}$.

Portanto, como Barros-Platiau bemlembra, para que seja alcançada a governança descrita por Rosenau, é necessário considerarmos a questão do multilateralismo jurídico, político e econômico, causada pela fragmentação do poder e das fontes reguladoras globais, podendo ser uma possível contribuição ao desenvolvimento do direito internacional ambiental $^{18}$.

Nesse sentido, é válido salientar que não só os Estados são responsáveis pela tomada de decisões e formação de políticas internacionais. Existem diversas organizações extra-governamentais que exercem influência nas questões ambientais globais. Talvez a mais importante destas organizações seria o Programa das Nações Unidas sobre Meio Ambiente - PNUMA, que surge no momento em que a ONU, mediante sua resolução No 2997 de dezembro de 1972, reconhece a "necessidade de elaborar prontamente e efetivamente a implementação, pelos governos e pela comunidade internacional de medidas destinadas a salvaguardar e melhorar o ambiente em prol das gerações presentes e futuras da humanidade"19.

Conforme Dinh, o PNUMA tem como principais funções

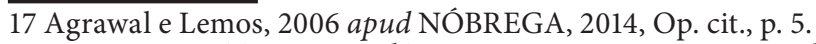

18 BARROS-PLATIAU, Ana Flávia. Novos atores, governança global e o direito internacional ambiental. 2001, p. 6. Disponível em: <http://www.egov.ufsc.br/portal/sites/default/files/ anexos/31997-37543-1-PB.pdf $>$. Acesso em 21 de novembro de 2015.

19 Disponível em: <http://www.un-documents.net/a27r2997.htm >. Acesso em 25 de novembro de 2015. Tradução nossa. 
[...] a promoção da cooperação internacional no domínio do ambiente e as de recomendar as políticas para este fim (numerosos instrumentos jurídicos foram negociados sob os seus auspícios ou por sua iniciativa); de recomendar os programas relativos ao ambiente no quadro das Nações Unidas e de supervisionar a sua aplicação; de "seguir a situação do ambiente no mundo" e de encorajar a pesquisa e a difusão de informação neste domínio; de avaliar os incidentes políticos e as medidas nacionais e internacionais em matéria de ambiente sobre os países em desenvolvimento e problemas de custos suplementares resultante para estes países; e de gerar os programas do Fundo do ambiente ${ }^{20}$.

Contudo, em sentido contrário, há quem questione se seria vantajosa a admissão de vários atores no tratamento das questões ambientais. Conforme explanado anteriormente, o desenvolvimento sustentável baseia-se em três pilares: o desenvolvimento ambiental, o social e o econômico; havendo o desbalanceamento de algum destes parâmetros, existiria o risco de que alguma nação em desenvolvimento fosse prejudicada. Argumenta-se que "toda essa gama de processos, ações e aparatos institucionais nem sempre se complementam, o que acaba por dificultar os propósitos pelos quais foram criados [...]: proteção ambiental, crescimento econômico sustentável e desenvolvimento socialmente justo" 21 .

O FBOMS - Fórum Brasileiro de ONGs e Movimentos Sociais para o Meio Ambiente e o Desenvolvimento, em conjunto com o Vitae Civilis Instituto para o Desenvolvimento, Meio Ambiente e Paz, debatendo sobre o tema, suscita que

Um dos motivos para esta situação pode ser identificado na complexa fragmentação da governança ambiental internacional, demonstrando múltiplas atribuições e papéis, distribuídos em instituições de várias esferas e segmentos e a falta de coordenação. A maioria dos acordos ambientais não tem metas claras que facilitem e viabilizem a implementação das medidas propostas. Tampouco há garantia de financiamento adequado para a implementação dos mesmos, e os países em desenvolvimento sofrem com os altos requisitos para cumprir com os relatórios de implementação e até mesmo com a garantia de participação nas conferências e reuniões de negociação sobre os acordos ${ }^{22}$.

20 DINH, 2003, Op. cit., p. 1304.

21 NÓBREGA, 2014, OP. cit., p. 5.

22 NEUHAUS, Esther; BORN, Rubens Harry. Governança ambiental internacional. Perspectivas, cenários e recomendações. Fórum Brasileiro de ONGs e Movimentos Sociais para o Meio Ambiente e o Desenvolvimento. Brasília/São Paulo, 2007, p. 6. Disponível em $<$ https://www.scribd.com/fullscreen/7916316?access_key=key-vvj1vsspd7egdvnizh4>. Acesso em 21 de novembro de 2015. 
Percebe-se, portanto, que há um conflito de ideias com relação à implementação de um sistema de governança global ambiental, sendo certo que esta depende totalmente da maneira como é implementada para que consiga alcançar seus objetivos na efetivação do desenvolvimento sustentável.

\section{PERSPECTIVAS DOS BRICS}

Antes de passarmos à análise da relação dos países que compõem os BRICS com o desenvolvimento sustentável, vale tecer alguns comentários acerca da origem, peculiaridades etc. do referido bloco.

\subsection{Origem}

A ideia de um grupo econômico denominado de BRICS surgiu no trabalho do americano Jim O'Neil, então economista-chefe da Goldman Sachs, em um estudo publicado em 2011 intitulado "Building Better Global Economic BRICs". Originalmente, incluíam-se somente o Brasil, a Rússia, a Índia e a China, sendo durante a III Cúpula do mesmo, em 2011, que a África do Sul foi admitida no grupo (mudando a sigla para BRICS).

Segundo o Instituto de Pesquisa Econômica Aplicada - IPEA, os BRICS possuem um expressivo peso econômico na escala global, representando 65\% da expansão do PIB mundial entre 2003 e 2007. Diz ainda que, em 2003, os BRICs respondiam por $9 \%$ do PIB mundial, e em 2009 o valor aumentou para 14\%. Em 2010, o PIB conjunto dos cinco países, incluindo a África do Sul, representou 18\% da economia mundial, já superando o PIB dos Estados Unidos e o da União Europeia ${ }^{23}$.

Também conforme o IPEA, o BRICS tem um caráter informal, pois não possui documento constitutivo nem funciona com um secretariado fixo. O que sustenta o agrupamento é a vontade política de seus membros, apresentando um grau de institucionalização que se vai definindo, à medida que os cinco países intensificam sua interação ${ }^{24}$.

Azahaf et al., em seu relatório sobre a capacidade de governança dos BRICS, discorre sobre a importância de estudarmos tal agrupamento. Segundo este,

Os poderes rapidamente emergentes do Brasil, Rússia, Índia, China e África do Sul (BRICS) são muitas vezes considerados como responsáveis no processo para mudar o mapa político e econômico do século 21.

23 BRASIL. MINISTÉRIO DO PLANEJAMENTO. IPEA, INSTITUTO DE PESQUISA ECONÔMICA APLICADA. Conheça os BRICS - Brasil, Rússia, Índia, China e África do Sul. Rio de Janeiro, 2014. Disponível em <http://www.ipea.gov.br/forumbrics/pt-BR/conheca-osbrics.html $>$. Acesso em 23 de novembro de 2015.

24 Ibidem. 
Em particular, o crescimento econômico sem precedentes históricos observada desde a década de 1990, na figura dos "gigantes despertados" China, Índia e Brasil não só tem estimulado o interesse dos investidores nestes mercados futuros, como surpreendeu os mundos da política, da ciência, da economia e da mídia. A importância econômica global das nações BRICS é indiscutível ${ }^{25}$.

Desse modo, tendo em vista a amplitude e a dimensão da coalizão formada pelo BRICS, tal grupo surge no cenário internacional com potencialidade para se tornar um grande ator internacional. Os países que o compõe têm um enorme desafio no que se refere à boa Governança política, econômica, social e ambiental. Mesmo possuindo um enfoque maior na esfera econômico-financeira, os BRICS têm a capacidade de criar uma nova ordem internacional que preza pela proteção do meio ambiente e objetivação do desenvolvimento sustentável, elementos que urgem pela tomada de decisões urgentes, de um cunho mais prático.

\subsection{Os BRICS como possíveis atores na governança ambiental}

Já demonstrada a importância econômica e política do agrupamento objeto do presente estudo, nos cabe agora mostrar a forma que é conduzido o desenvolvimento ambiental e, consequentemente, o desenvolvimento sustentável.

É notório que os BRICS possuem patrimônios ecológicos inigualáveis. Aliados a extensões territoriais de dimensões continentais, são responsáveis por abrigar milhares de espécies de fauna e flora únicas. Contudo, ao contrário do que se espera, os BRICS estão apenas iniciando a trilhar o caminho da sustentabilidade. Sua constante presença em convenções internacionais sobre o meio ambiente, como a Conferência das Nações Unidas para o Desenvolvimento Sustentável, conhecida como Rio+20, em 2012, e os marcantes debates sobre questões ambientais servem de alento para quem espera que o bloco avance no estabelecimento de uma boa governança ambiental.

Foi exatamente antes daquele evento, a Rio+20, em 2011, que Santos Júnior publicou um artigo analisando a transição das políticas, dos países que compõem os BRICS, voltadas ao desenvolvimento econômico para uma política voltada ao desenvolvimento ambiental, a qual o autor chama de "economia verde". Diz ele que:

25 AZAHAF, N. et al. Governance Capacities in the BRICS. Sustainable Governance Indicators. Gütersloh: [s.n.], 2012, p. 9. Disponível em: <http://www.sgi-network.org/brics/ pdf/Governance\%20Capacities\%20in\%20the\%20BRICS.pdf $>$. Acesso em 24 de novembro de 2015. 
No que se refere especificamente aos países BRICS, a falta de consenso na transição para a economia verde gira justamente ao redor do princípio da responsabilidade comum, porém diferenciada. Nesse sentido, no entendimento indiano, por exemplo, a economia verde pode vir a significar um entrave ao desenvolvimento econômico. No entanto, é de acordo que todos os cinco países devem adequar suas economias à parâmetros sustentáveis, já que, em conjunto, os BRICS apresentam altas taxas de emissão de gás carbônico e outros gases poluentes e de utilização de recursos não-renováveis para geração de energia e consumo ${ }^{26}$.

Dessa forma, fica evidenciado certo contraponto de ideias entre os países-membros do grupo. Enquanto que uns, como Brasil e África do Sul, prezam pelas políticas voltadas ao desenvolvimento sustentável, outros como a Índia e China, países marcados pela industrialização, têm como prioridade o desenvolvimento econômico.

Mesmo assim, o grupo tem mostrado sua preocupação com o crescimento sustentável. Como bem lembra Nóbrega, foi durante a "Conferência BRICS no Século 21" em maio de 2014, que surgiu o denominado Consenso do Rio. Este documento, assinado por especialistas e intelectuais das cinco nações, objetiva promover o crescimento sustentável, mediante forte presença do Estado, redução da pobreza e desigualdade social e crescimento dos empregos, sendo apresentada por meio de onze estratégias econômicas políticas e científicas ${ }^{27}$.

Por fim, vale observar, novamente invocando Nóbrega, que:

[...] apesar dos BRICS serem um agrupamento político de cooperação recente, essas e demais iniciativas que deverão ser tomadas, nos campos político-econômico e socioambiental revelam a maior interação entre os Estados membrose, por consequência, o maior grau deinstitucionalização que tenderá aumentar, a medida de seus acordos. Entretanto, mais importante que a participação em encontros de relevância internacional sobre questões ambientais é o comprometimento desses Estados e dos BRICS, enquanto agrupamento, em relação aos acordos firmados e suas políticas internas ${ }^{28}$.

Passaremos, a seguir, à análise da influência das políticas de desenvolvimento sustentável nos países que compõem os BRICS.

26 SANTOS JÚNIOR, Sérgio Veloso; BOCAYUVA, Pedro Claudio Cunca. Os BRICS e a Economia Verde: Rumo à Rio+20. Núcleo de Desenvolvimento Urbano e Sustentabilidade BRICS Policy Center. Rio de Janeiro, 2011, p. 3. Disponível em <http://bricspolicycenter.org/ homolog/uploads/trabalhos/255/doc/2091916855.pdf >. Acesso em 23 de novembro de 2015. 27 NÓBREGA, 2014, Op. cit., p. 11.

28 Ibíd., p.12-13. 


\subsection{O desenvolvimento sustentável nos países do BRICS}

O tema do desenvolvimento sustentável encontra-se presente amiúde nas declarações conjuntas dos líderes dos BRICS. Em todas as Cúpulas dos grupos, da primeira (Ecaterimburgo, de 16 de junho de 2009) até a nona (Xiamen, de 04 de setembro de 2017), tal tema foi destacado. A seguir, demonstraremos brevemente alguns trechos nos quais foi discutido o desenvolvimento sustentável.

A declaração conjunta de Sanya (14 de abril de 2011), em seu ponto 23 , mostra o comprometimento dos países integrantes do bloco em estabelecer metas e alcançar resultados no contexto do desenvolvimento sustentável:

23. A realização do desenvolvimento sustentável, como ilustram a Declaração do Rio sobre Meio Ambiente e Desenvolvimento, a Agenda 21, o Plano de Implementação de Joanesburgo e os tratados multilaterais ambientais, deve ser importante veículo para a promoção do desenvolvimento econômico. China, Rússia, Índia e África do Sul [...] estão dispostos a trabalhar com o Brasil para chegar a um compromisso político novo e alcançar resultados positivos e práticos nas áreas de crescimento econômico, desenvolvimento social e proteção ambiental no quadro do desenvolvimento sustentável ${ }^{29}$.

Já na declaração conjunta de Nova Délhi (29 de março de 2012), em seu ponto 28 , expõe claramente o conceito da equidade intergeracional:

28. A aceleração do crescimento e desenvolvimento sustentável, em conjunto com a segurança alimentar e energética, encontram-se entre os desafios mais importantes da atualidade e são centrais para o tratamento do desenvolvimento econômico, erradicação da pobreza, combate à fome e desnutrição em muitos países em desenvolvimento. Faz-se premente a criação de empregos necessários à melhoria dos níveis de vida. $\mathrm{O}$ desenvolvimento sustentável é também um elementochave de nossa agenda para a recuperação global e investimentos para estimular o crescimento futuro. Temos essa responsabilidade para com nossas futuras gerações ${ }^{30}$.

Por último, a declaração conjunta de Xiamen, no ponto 14, reafirma o compromisso perante as três dimensões do desenvolvimento sustentável:14. Reafirmamos o nosso compromisso de implementar totalmente a Agenda 2030 para o Desenvolvimento Sustentável. Defenderemos também

29 BAUMANN, Renato et al. BRICS: estudos e documentos. Brasília: FUNAG, 2015. p. 179-180.

30 Ibíd., p. 194. 
um desenvolvimento equitativo, aberto, abrangente, inclusivo e impulsionado pela inovação, a fim de alcançar o desenvolvimento sustentável em suas três dimensões - econômica, social e ambiental - de forma equilibrada e integrada ${ }^{31}$.

Após a leitura dos textos destacados, nota-se a importância do tema nas reuniões de seus membros e na elaboração dos respectivos planos de ações. Tais pontos apontam a preocupação dos BRICS com o panorama sustentável e a disposição para elaborar políticas que venham a promover seu desenvolvimento.

A seguir, veremos brevemente como cada país que compõe o BRICS age com relação ao tema em destaque.

\subsubsection{Brasil}

O Brasil é, dentre os BRICS, o melhor colocado para alcançar soluções sociais em longo prazo. Afirma Azahaf et al., que "na visão dos especialistas, o Brasil tem a perspectiva futura mais promissora de todos os países do BRICS, uma qualidade que aplica às tendências atuais em áreas da política importantes, bem como, na qualidade de sua capacidade de governança" ${ }^{32}$.

Apesar de ainda enfrentar algumas dificuldades relacionadas ao planejamento estrutural e estratégico, e, também com relação às desigualdades sociais, sobretudo na área da educação, o Brasil viu nos últimos anos um aumento de seus indicadores sociais e da capacidade econômica das classes baixa e média, tornando os brasileiros mais conscientes com o ambiente ao seu redor e mais sensíveis às questões ambientais.

Assim, o governo passou a promover mais políticas voltadas à preservação e desenvolvimento ambientais. Um bom exemplo seria o estímulo do governo ao uso de fontes de energia renováveis, como a hidroelétrica e de biocombustíveis, graças ao seu enorme potencial natural, correspondendo a $40 \%$ do abastecimento de energia no país, gerando, consequentemente, baixíssimas emissões de gases que contribuem com o efeito estufa.

Também, conforme lembra o estudo realizado pela Organização para Cooperação e Desenvolvimento Econômico - OCDE, o Brasil estabeleceu em 1981 o Conselho Nacional do Meio Ambiente CONAMA, e posteriormente o Ministério do Meio Ambiente - MMA, fortalecendo a agenda ambiental nacional. Tais órgãos governamentais, que antes viviam isolados, passaram a participar de diálogos entre

31 BRASIL. MINISTÉRIO DAS RELAÇÕES EXTERIORES. IX Cúpula do BRICS Declaração de Xiamen - Xiamen, China, 4 de setembro de 2017, p. 8. Disponível em $<$ http:// www.itamaraty.gov.br/pt-BR/notas-a-imprensa/17384-nona-cupula-do-brics-declaracao-dexiamen-xiamen-china-4-de-setembro-de-2017>

32 AZAHAF et al., 2012, Op. cit. p.8. Tradução nossa. 
os outros ministérios e representantes do governo, integrando as problemáticas ambientais às políticas sociais e econômicas ${ }^{33}$.

Mantendosuaconsciênciaambientalnoplanointernacional,oBrasil é um grande defensor de soluções mais integradas internacionalmente, voltadas à cooperação e coordenação entre os agentes internacionais na consecução de um desenvolvimento sustentável equilibrado. Também, defende a inclusão dos países em desenvolvimento nos órgãos internacionais, observando suas especificidades.

Apesar de suas qualidades, o Brasil ainda precisa alcançar sua estabilidade política e diretiva para alcançar o pleno desenvolvimento sustentável, bem como desenvolver sua infra-estrutura e fortalecer em termos de planejamento estratégico.

\subsubsection{Rússia}

A Rússia apresenta o desempenho mais fraco no conjunto dos BRICS no que se refere à adoção de políticas ambientais e sustentáveis, tendo como maior defeito a ingerência do governo bem como a falta de planejamento estratégico.

Com a queda do regime soviético, os níveis de emissão de gases nocivos ao meio ambiente decaíram, devido à desorganização do regime, levando os governos seguintes a continuarem preservando os baixos índices de emissão, constituindo uma boa atitude do país. Também, conforme Silva:

A prevenção passou a ser um ponto importante. O princípio de fortalecimento da responsabilidade ambiental, das empresas e da atividade econômica em geral ganhou expressão no direito russo que garantia ao Estado um papel de punir os que ferissem "o interesse geral" ou que desenvolvessem atividades com risco para a sociedade, a fauna, a flora e o futuro ${ }^{34}$.

Apesar disso, o acesso às tomadas de decisão no país é muito restrito, tendo como consequência a inexistência de um ministério de meio ambiente independente e a falta de especialistas na área. Ainda

33 ORGANIZAÇÃO PARA COOPERAÇÃO E DESENVOLVIMENTO ECONÔMICO. OECD Environmental Performance Reviews: Brazil. Paris: OECD Publishing, 2015, p. 26. Disponível em: <http://www.keepeek.com/Digital-Asset-Management/oecd/environment/ oecd-environmental-performance-reviews-brazil-2015_9789264240094-en>. Acesso em 24 de novembro de 2015 .

34 SILVA, Antônio Marcos Dutra da; HERZ, Monica. Rio+20: a Rússia e a Estrutura Institucional Internacional para o Desenvolvimento Sustentável. Núcleo de Desenvolvimento Urbano e Sustentabilidade BRICS Policy Center. Rio de Janeiro, abr. 2012, p. 2. Disponível em <http://bricspolicycenter.org/homolog/uploads/trabalhos/3999/doc/1576392673.pdf >. Acesso em 24 de novembro de 2015. 
de acordo com Silva ${ }^{35}$, "para alguns tomadores de decisão russos, o comprometimento para com metas de redução de poluição pode limitar crescimento econômico, ao atingir a capacidade produtiva nacional". Da mesma forma, praticamente não há participação da sociedade civil, ficando a Rússia à frente apenas da China, dentre os participantes do agrupamento.

Assim, com uma política contraditória e totalmente intransigente, é praticamente impossível o surgimento de políticas prospectivas, na Rússia atual, que visem o desenvolvimento sustentável ${ }^{36}$.

\subsection{3. Índia}

A Índia possui certos problemas sociais, principalmente com relação à pobreza, desigualdade social e corrupção. Porém, surge como uma figura promissora em se tratando da promoção do desenvolvimento sustentável, desde que consiga superar tais problemas.

Grande parte da expectativa sobre a India reside na consistência de seu planejamento estratégico, o melhor dos BRICS conforme os especialistas. Também, o país é bastante fortalecido no que tange a participação da sociedade civil. Santos Júnior afirma que:

[...] o governo, em conjunto com diversos setores da sociedade civil, organizou a Coalizão para a Economia Verde - CEV. Através da CEV, o governo indiano espera acelerar a transição para uma economia verde inclusiva. A coalizão promove o entendimento comum, a criatividade e a capacidade de inovação entre setores da sociedade política e civil em direção a um paradigma sustentável de desenvolvimento econômico. Dessa forma, o governo indiano mantém sua soberania na condução para a economia verde, sem ferir seus planos de crescimento. Um dos principais objetivos da coalizão é identificar temas e áreas estratégicas que possibilitem uma transição em harmonia com a necessidade de aceleração da economia indiana ${ }^{37}$.

Entretanto, no cenário internacional, a Índia se posiciona de forma receosa sobre a transição de políticas voltadas ao desenvolvimento econômico para as políticas voltadas à preservação ambiental, sendo uma ferrenha defensora do "princípio das responsabilidades comuns, porém diferenciadas". Sobre este princípio, Florentino explica:

[...] tem papel central no posicionamento indiano a defesa de uma estrutura institucional que contemple o princípio de "responsabilidades

35 Ibíd., p. 4,

36 AZAHAF et al., 2012, Op. cit., p. 6.

37 SANTOS JÚNIOR, 2011, Op. cit., p. 8. 
comuns, porém diferenciadas" (RCPD). Esse princípio, na interpretação da Índia e dos países em desenvolvimento como um todo, estabelece que os países desenvolvidos, cuja industrialização foi anterior e mais duradoura do que em países em desenvolvimento, possuem uma maior responsabilidade histórica sobre a degradação ambiental e, com isso, devem contribuir com uma maior parcela de esforços para a promoção do desenvolvimento sustentável. O princípio, contudo, não exime, por completo, os países em desenvolvimento de contribuírem para a proteção ambiental ${ }^{38}$.

Diante o exposto, fica claro que a Índia surge no cenário ambiental internacional como uma esperança de fortalecimento das políticas voltadas ao desenvolvimento sustentável, desde que consiga amenizar seus problemas sociais e passe a adotar políticas de accountability, para auxiliar no combate à corrupção.

\subsubsection{China}

Com relação à China, os especialistas do Bertelsmann Stiftung apresentam uma análise ambivalente. Se, por um lado, o país apresenta um enorme potencial diante de sua capacidade para tomar decisões estratégicas, por outro lado peca enormemente em suas condições sociais, com elevados índices de desigualdade social e regional, desenvolvimento demográfico e corrupção, e poluição ambiental ${ }^{39} \mathrm{em}$ decorrência de sua enorme indústria.

Consoante o relatório supracitado:

O país se destaca por sua política de planejamento estratégico em longo prazo, e o seu sistema hierárquico de coordenação interministerial funciona relativamente bem. No entanto, é questionável até que ponto o governo realiza consultas a fontes acadêmicas independentes. Como a Índia, o sistema político de vários níveis traz grandes diferenças regionais na qualidade do governo, que por sua vez tem um efeito negativo sobre a qualidade dos serviços públicos nas áreas de periferia ${ }^{40}$.

No quesito da luta contra a corrupção, a China falha no sentido de que naquele país não existem meios de comunicação livres e setores da sociedade civil independentes do Estado.

38 FLORENTINO, Lucas Perez; WALDELY, Aryadne Bittencourt e HERZ, Monica. Rio+20: a Índia e a Estrutura Institucional Internacional para o Desenvolvimento Sus-tentável. Núcleo de Desenvolvimento Urbano e Sustentabilidade BRICS Policy Center. Centro de Estudos e Pesquisas BRICS. 2012, p. 3. Disponível em <http://bricspolicycenter.org/homolog/uploads/ trabalhos/4000/doc/1876112887.pdf >. Aces-so em 24 de novembro de 2015.

39 AZAHAF et al., 2012, Op. cit., p. 6-7.

40 Ibíd., p. 7. Tradução nossa. 
Já no âmbito do desenvolvimento ambiental, essencial para o desenvolvimento sustentável, o governo chinês apresenta algumas boas políticas, como as que estimularam a diminuição de emissão de gases poluentes e o comprometimento de "promover reformas no sistema de impostos ambientais, reduzir as exportações de mercadorias produzidas a custa de alto consumo de energia e investimento de US\$300 bilhões para promover a economia verde" ${ }^{\text {"41 }}$. No plano internacional, o país defende o princípio das "responsabilidades comuns, porém diferenciadas" e cooperação entre as organizações internacionais sobre as questões ambientais, sobretudo nos países ainda em desenvolvimento, observando suas questões específicas.

Outro ponto importante, suscitado por Santos Júnior, diz respeito à crise econômica que atingiu as principais potências mundiais nos últimos anos. Diz o autor:

Todavia, com a crise econômica global atingindo os EUA e a União Europeia e amortecendo as perspectivas de crescimento global, o mundo se vira para a China e sua robusta economia como esperança para evitar uma recessão global. Esse quadro pode significar um impasse na transição da economia chinesa para padrões mais sustentáveis. Ainda assim, o governo chinês afirma que a transição para a economia verde deve ser priorizada em relação ao crescimento econômico por vias não sustentáveis ${ }^{42}$.

Sendo assim, a China se caracteriza como mais uma promessa dentre os BRICS. Apesar de seus problemas sociais e ambientais, o país tem consciência da necessidade de mudanças em suas políticas e se compromete a fazê-las, o que pode tornar-se possível já que o mesmo é bem desenvolvido economicamente.

\subsection{5. África do Sul}

A África do Sul figura uma posição mediana entre os países do BRICS. Como as demais nações do agrupamento, apresenta algumas questões sociais preocupantes, que, se contornadas, o país conseguirá atingir o desenvolvimento sustentável pleno.

Como pontos positivos de sua política nacional, Azahaf et al. cita que o governo tem realizado arranjos institucionais importantes, melhorando sua capacidade de planejamento estratégico, bem como são utilizados conhecimentos acadêmicos e há o envolvimento da sociedade civil e outros grupos interessados no processo de elaboração 
das políticas ${ }^{43}$. Ainda, segundo Santos Júnior:

Diferentemente dos outros países BRICS, a África do Sul entende que a transição para um modelo de desenvolvimento sustentável é uma oportunidade única para promover inclusão social ao mesmo tempo em que diminui os impactos das mudanças climáticas ${ }^{44}$.

Contudo,ogovernosul-africanopoderiamelhorarsignificativamente as áreas de coordenação interministeriais e de implementação de políticas. Juntamente com expressivos níveis de clientelismo, corrupção e nepotismo, o engajamento na causa sustentável se torna mais distante ${ }^{45}$.

No plano internacional, a África do Sul defende a governança internacional no auxílio aos países em desenvolvimento, coordenando os atos com os outros agentes e organizações internacionais, à medida das peculiaridades de cada nação.

Resta demonstrada, então, a relação dos países que compõem o BRICS com o desenvolvimento sustentável, e como estes se posicionam a respeito de uma boa governança ambiental internacional. Passaremos a seguir às conclusões.

\section{CONCLUSÃO}

Após a análise do presente estudo, podemos entender os principais aspectos do meio ambiente, do desenvolvimento sustentável e da governança ambiental internacional e como estes institutos se apresentam nos países que compõem o agrupamento dos BRICS.

Podemos concluir, então, que os BRICS consistem em reais atores no cenário mundial no que diz respeito ao desenvolvimento sustentável. É certo que os cinco países têm seus defeitos e impedimentos nas três esferas do desenvolvimento sustentável: o desenvolvimento econômico, social e ambiental. Porém, todos aqueles, uns mais que outros, vêm apresentando políticas e soluções que visam reverter este cenário.

Políticas orientadas ao combateà corrupção, a redução da desigualdade social e regional; e um maior diálogo entre os órgãos governamentais e com a sociedade civil pode resolver diversos problemas sociais presentes naqueles países. Já no sentido do desenvolvimento ambiental, seria de enorme valia a tomada de decisões voltadas ao fortalecimento das políticas internas ambientais, como a redução de emissão de gases nocivos à camada de ozônio e que contribuem com o efeito estufa, modernização das indústrias e um efetivo planejamento estratégico.

Internacionalmente, o grupo tem o dever de focar em uma

43 AZAHAF et al., 2012, Op. cit. p. 7.

44 SANTOS JÚNIOR, 2011, Op. cit., p. 10.

45 AZAHAF et al., 2012, Op. cit. p. 7. 
agenda sustentável, aproveitando o protagonismo de seus membros no cenário internacional para coordenar seus objetivos comuns e dialogar com as outras nações e organizações internacionais, mostrando seu comprometimento com a causa sustentável.

Por enquanto, não há um consenso entre os membros em como agir neste sentido, mas, com as constantes reuniões e Cúpulas, a coalizão será cada vez mais fortificada, abrindo os caminhos para as tomadas de decisões para alcançar o desenvolvimento sustentável pleno.

\section{REFERÊNCIAS BIBLIOGRÁFICAS}

AZAHAF, N. et al. Governance Capacities in the BRICS. Sustainable Governance Indicators. Gütersloh: [s.n.], 2012, p. 9. Disponível em: $<$ http://www.sgi-network.org/brics/pdf/Governance\%20Capacities\%20 in $\% 20$ the\%20BRICS.pdf>

BARROSO, Luís Roberto. A Dignidade da Pessoa Humana no Direito Constitucional Contemporâneo: Natureza Jurídica, Conteúdos Mínimos e Critérios de Aplicação. [s.l.], 2010, BARROSO, 2010, p. 14-15. Disponível em: <https://www.luisrobertobarroso.com.br/wpcontent/uploads/2010/12;Dignidade_texto-base_11dez2010.pdf $>$

BARROS-PLATIAU, Ana Flávia. Novos atores, governança global e o direito internacional ambiental. 2001, p. 6. Disponível em: $<$ http://www. egov.ufsc.br/portal/sites/default/files/anexos/31997-37543-1-PB.pdf>

BRASIL. MINISTÉRIO DAS RELAÇÕES EXTERIORES. IX Cúpula do BRICS - Declaração de Xiamen - Xiamen, China, 4 de setembro de 2017, p. 8. Disponível em <http://www.itamaraty.gov.br/pt-BR/notasa-imprensa/17384-nona-cupula-do-brics-declaracao-de-xiamenxiamen-china-4-de-setembro-de-2017>

BRASIL. MINISTÉRIO DO PLANEJAMENTO. IPEA, INSTITUTO DE PESQUISA ECONÔMICA APLICADA. Conheça os BRICS - Brasil, Rússia, India, China e África do Sul. Rio de Janeiro, 2014. Disponível em <http://www.ipea.gov.br/forumbrics/pt-BR/conheca-os-brics.html>

CARVALHO, Sonia Aparecida e ADOLFO, Luiz Gonzaga Silva. Sustentabilidade e tecnologia: perspectivas para o direito contemporâneo. Direito e desenvolvimento sustentável: a (necessária) proteção jurídica da biotecnologia e a (necessária) regulamentação do acesso à biodiversidade e aos conhecimentos tradicionais. Passo Fundo: IMED, 2013, p. 171.

DINH, Nguyen Quoc; DAILLIER, Patrick e PELLET, Allain. Direito Internacional Público. $2^{\mathrm{a}}$ ed. Lisboa: Fundação Calouste Gulbenkian, 2003. 
FIORILLO, Celso Antonio Pacheco. Curso de direito ambiental brasileiro. $15^{\text {a }}$ ed. São Paulo: Saraiva, 2014.

FLORENTINO, Lucas Perez; WALDELY, Aryadne Bittencourt e HERZ, Monica. Rio+20: a India e a Estrutura Institucional Internacional para o Desenvolvimento Sus-tentável. Núcleo de Desenvolvimento Urbano e Sustentabilidade BRICS Policy Center. Centro de Estudos e Pesquisas BRICS. 2012, p. 3. Disponível em <http://bricspolicycenter.org/ homolog/uploads/trabalhos/4000/doc/1876112887.pdf>

GUERRA, Sidney e EMERIQUE, Lilian Márcia Balmant. O Princípio da Dignidade da Pessoa Humana e o Mínimo Existencial. Revista da Faculdade de Direito de Campos. 2006, vol 9, p. 382. Disponível em $<$ http://fdc.br/Arquivos/Mestrado/Revistas/Revista09/Artigos/Sidney. pdf $>$

NEUHAUS, Esther; BORN, Rubens Harry. Governança ambiental internacional. Perspectivas, cenários e recomendações. Fórum Brasileiro de ONGs e Movimentos Sociais para o Meio Ambiente e o Desenvolvimento. Brasília/São Paulo, 2007, p. 6. Disponível em <https://www.scribd.com/fullscreen/7916316?access_key=keyvvj1vsspd7egdvnizh4>

NÓBREGA, Mariana de Oliveira e LACERDA, Jan Marcel de Almeida Freitas. Governança global ambiental e os BRICS: perspectivas e desafios para uma futura agenda sustentável. In: $2^{\circ}$ Seminário de Relações Internacionais: Graduação e Pós-graduação "Os BRICS e as Transformações da Ordem Global”. João Pessoa - P: Associação Brasileira de Relações Internacionais, 2014., p. 2-3. Disponível em <http:// www.seminario2014.abri.org.br/resources/anais/21/1412110561_ ARQUIVO_Artigo-ABRI-BRICSeGovernancaGlobalAmbiental.pdf>

ORGANIZAÇÃO PARA COOPERAÇÃO E DESENVOLVIMENTO ECONÔMICO. OECD Environmental Performance Reviews: Brazil. Paris: OECD Publishing, 2015, p. 26. Disponível em: <http://www. keepeek.com/Digital-Asset-Management/oecd/environment/oecdenvironmental-performance-reviews-brazil-2015_9789264240094-en>

SANTOS JÚNIOR, Sérgio Veloso; BOCAYUVA, Pedro Claudio Cunca. Os BRICS e a Economia Verde: Rumo à Rio+20. Núcleo de Desenvolvimento Urbano e Sustentabilidade BRICS Policy Center. Rio de Janeiro, ago. 2011, p. 3. Disponível em <http://bricspolicycenter.org/ homolog/uploads/trabalhos/255/doc/2091916855.pdf $>$

SILVA, Antônio Marcos Dutra da; HERZ, Monica. Rio+20: a Rússia e a Estrutura Institucional Internacional para o Desenvolvimento 
Sustentável. Núcleo de Desenvolvimento Urbano e Sustentabilidade BRICS Policy Center. Rio de Janeiro, abr. 2012, p. 2. Disponível em <http://bricspolicycenter.org/homolog/uploads/trabalhos/3999/ doc/1576392673.pdf>

WEISS, Thomas G. The UN's Role in Global Governance. Briefing Note Number 15. Nova Iorque, 2009. Disponível em: <http://www.unhistory. org/briefing/15GlobalGov.pdf>

\section{RESUMO BIOGRÁFICO}

Renato Pinto Cavalcanti é Bacharel em Direito pela FACISA - Faculdade de Ciências Sociais Aplicadas, atualmente atuando como Advogado particular. 